\title{
(Arte)
}

INFORMES DE INVESTIGACIÓN

\section{De la injuria al orgullo: Las representaciones artísticas de los 41 maricones (1901-2016)}

\author{
Helder Díaz Cisneros \\ Universidad de Sonora. Maestría en Humanidades \\ helder009@hotmail.com
}

Resumen. En este artículo hacemos un breve recorrido por las representaciones artísticas que a lo largo de más de una centuria (1901-2016) se han inspirado en los protagonistas de la redada del "baile de los 41 maricones", acontecimiento histórico que marcó un hito en la historia de la homosexualidad en México y de las representaciones de sus minorías sexuales, que van desde la caricatura injuriosa hasta la apropiación del símbolo 41 con el fin de hacer de ese acontecimiento un motivo de orgullo.

Palabras clave: representación, homosexualidad, caricatura, injuria, apropiación, orgullo.

\section{Introducción}

La madrugada del domingo 17 de noviembre de 1901 ocurrió un escándalo de grandes proporciones en la capital del México porfiriano. La policía realizó una redada en una fiesta que se realizaba dentro de una casona de la calle de la Paz, arrestando a un total de 41 hombres, 19 de ellos vestidos de mujer. A los pocos días la prensa publicó la historia, provocando gran expectación entre la población, en gran medida gracias al sarcasmo, ironía y burla con que trataron el tema y a la proliferación de rumores y chismes que se convirtieron en leyenda. Con esto me refiero específicamente a que, en las primeras notas, se publicó que los detenidos habían sido 42 hombres y posteriormente el número se redujo a 41 , algo que desató el rumor de que el supuesto número 42 era Ignacio de la Torre, yerno del presidente Porfirio Díaz, quien ordenó que desaparecieran cualquier registro de su participación y detención en dicho baile. Sin embargo, el hecho importante es que estos acontecimientos dieron pie a la aparición de las primeras representaciones de la homosexualidad masculina en el imaginario nacional y se convirtieron en un hito en la historia de la comunidad LGBTIQ $^{1}$ mexicana.

El llamado "baile nefando" ha sido uno de los temas que más atención ha despertado en quienes se dedican al estudio e investigación de la historia de la homosexualidad en México. Los trabajos de Carlos Monsiváis (2010, 2013), Robert McKee Irwin (2013), Miguel Hernández Cabrera (2001), y más recientemente Juan Carlos Harris (2016), son algunos de los más importantes y hemos recurrido a ellos para la escritura de este artículo que pretende ser un breve recorrido por las representaciones artísticas que a lo largo de más de una centuria se han inspirado en los protagonistas de aquel "baile escandaloso".

\footnotetext{
${ }^{1}$ Sigla utilizada para designar a la comunidad de personas pertenecientes a las diferentes minorías sexuales y de género: lesbianas, gays, bisexuales, trans (travestis, transgénero, transexuales), intersexuales y queer.
} 


\section{Las caricaturas y la injuria}

Las primeras representaciones de este acontecimiento histórico fueron las ilustraciones caricaturescas de José Guadalupe Posada que aparecieron en varios folletos que circularon masivamente por las calles de la ciudad de México. Las ilustraciones venían acompañadas de versos irónicos que contaban la historia de lo sucedido en la calle de la Paz y los días siguientes, mofándose de sus protagonistas, a quienes apodan con grandes letras: "Los 41 maricones". Con esto vemos que, como menciona Didier Eribon en sus Reflexiones sobre la cuestión gay (2001), con respecto a la homosexualidad, en el principio está la injuria, la cual es un acto simbólico y de poder que no solamente describe sino que asigna a su destinatario un lugar determinado en el mundo; su función es instituir y perpetuar la separación entre los "normales" y aquellos "estigmatizados" (Eribon, p. 29). La injuria verbal es reforzada por la imagen, en especial la imagen caricaturesca.

La caricatura se aproxima a la injuria, como sugieren Ernst Kris y Ernst Gombrich inspirándose en los análisis de Freud sobre las "agudezas".

Freud definía la "agudeza" como una especie de exutorio para las pulsiones hostiles, una "alusión" a un insulto no dicho que permanece en su segundo plano. Kris y Gombrich interpretan la "caricatura" como el equivalente en el ámbito visual de semejante mecanismo. Es una auténtica agresión simbólica, ejerce una violencia y se enmarca en la filiación de las "imágenes difamatorias" de la Edad Media. La caricatura homófoba es una "difamación", se inscribe en el horizonte de la injuria y apela a los esquemas mentales que permiten hacer reír a propósito de los homosexuales. Expresa la inferioridad asignada a la homosexualidad en la sociedad y perpetúa las estructuras mentales que sustentan dicha inferioridad. (Eribon, 2001: 102-103)

Monsiváis menciona que fueron ocho o diez folletos con ilustraciones de Posada los que se publicaron, pero los que se han difundido más ampliamente son tres, el de la representación del baile de la calle de la Paz, el que representa su humillación pública, barriendo las calles de la ciudad de México y la que representa su partida a Yucatán, a donde 19 de los 41 maricones fueron enviados como castigo para formar parte de la gleba en la guerra de castas que aún se estaba dando en la península (Harris, 2016).

Estas imágenes caricaturescas fueron determinantes para la difusión y aceptación social del estereotipo del hombre homosexual como un hombre afeminado al que le gusta travestirse. Un afeminamiento entendido como un rasgo de inferioridad que debe ser sujeto de juicio y burla. Como la que volvió a realizar Posada en 1907 retomando las figuras caricaturescas de los 41 para hacer una crítica al feminismo en su grabado "El feminismo se impone" (2), en el que se observa la imagen de un enorme número 41 en cuyo alrededor se encuentran hombres travestidos realizando labores tradicionalmente asignadas a las mujeres, y es acompañado de los siguientes versos: "Mientras la mujer asiste al taller y a la oficina / y de casimir se viste / y de la casa desiste / y entra airosa a la cantina / el hombre barbilampiño / queda haciendo el desayuno / cose, plancha y cuida al niño / y todos con gran cariño / le llaman cuarenta y uno" (McKee, 2013: p. 18) .

\footnotetext{
${ }^{2}$ Véase: "El feminismo se impone". Fuente: http:// desastre.mx/mexico/la-redada-de-los-41-lamediatizacion-de-la-homosexualidad-en-mexico/ attachment/171116-feminismo-se-impone/
} 
Un año antes de la impresión de este gra bado fue publicada la novela Los cuarenta y uno: novela crítico-social, cuyo autor, que firmó con el seudónimo Eduardo A. Castrejón, es descrito por Monsiváis, con justa razón, como "un moralista sin talento literario” (p. 55). La novela está mal estructurada y los personajes son dibujados de manera muy simplista y reduccionista, pretendiendo enaltecer la superioridad moral de la clase trabajadora sobre la élite porfiriana a la que aparentemente pertenecían la mayoría de los 41 , quienes son descritos como hombres aburguesados, afeminados, inmorales y decadentes (McKee, 2013: p. 29).

La existencia, $\tan$ bella, $\tan$ harmoniosa, tan dulce y tierna para los hombres honrados y trabajadores que llevan una vida de actividad y de engrandecimiento, se convierte para los prostituidos refinados y ociosos, en un sarcasmo que mata la grandeza del alma y la potencia del cuerpo; y el vicio, ese vicio impuro que desciende hasta el último peldaño de la bajeza, los arrastra a la deshonra, les venda la razón, y aparece la bestia con toda su plástica grosera, con su materia virulenta y contagiosa. (Castrejón, 2013: p. 159)

Esa imagen del homosexual como perteneciente únicamente a una clase burguesa y ociosa -como si en la clase proletaria no existiera la homosexualidad- siguió difundiéndose después de la revolución mexicana con la divulgación oficial de la imagen del hombre viril de la clase trabajadora como la identidad deseada del hombre mexicano, imagen que alcanzó mayor difusión y aceptación gracias al cine de la llamada "época de oro".

Una de las muestras del desdén que en el México posrevolucionario se sentía por la homosexualidad es la pintura de Antonio
Ruiz, el Corcito, "Los paranoicos (los espiritufláuticos), los megalómanos"3 , realizada en 1941, justo en el cuarenta aniversario de la gran redada. En esta pintura el Corcito recurre, al igual que Posada, a la imagen caricaturesca. Con este recurso el autor ridiculiza a escritores, poetas y pintores homosexuales y a sus promotoras y mecenas. En ella encontramos en medio de una plaza pública a los herederos más notables del estigma: Salvador Novo, Xavier Villaurrutia, Agustín Lazo y Roberto Montenegro, todos del grupo Los Contemporáneos, junto a sus mecenas Antonieta Rivas Mercado y Lupe Marín, quienes desfilan contoneándose y moviendo las caderas, completamente retorcidos, como si no pudieran mantener la rectitud deseada socialmente. Con el colorido del cuadro pareciese que el Corcito hace alusión a la mariconería que caracterizaba al grupo de artistas y plasma otras figuras que pueden simbolizar los prejuicios del autor sobre la homosexualidad; como el balero, tradicional juguete que puede hacer alusión a los placeres anales, y el perro chihuahua, raza faldera y escandalosa por antonomasia, que con su cola parada observa a los protagonistas del cuadro con emoción (Marquet, 2009).

\section{Apropiación y resignificación}

Fue hasta los años sesenta y setenta del siglo pasado cuando el número 41 y los acontecimientos de noviembre de 1901 comenzaron a cobrar un nuevo significado, alejándose del estigma vergonzante. Con el surgimiento del Movimiento de Liberación Homosexual, que años después se conocería como LGBTIQ, se inició un proceso de apropiación y resignificación de la simbología injuriosa con la que el sistema heteronormativo ha

\footnotetext{
${ }^{3}$ Véase: "Los paranoicos (los espiritufláuticos), los megalómanos". Fuente: https://analmagazine.wordpress. com/2009/08/24/los-paranoicos-los-espiritiflauticos-los-megalomanos/
} 
atacado y estigmatizado a los no heterosexuales. Proceso que podríamos incluir dentro de lo que Judith Butler nombra "la deconstrucción política de lo queer" (p. 322 ), en la que palabras como marica, joto, y sobre todo gay y lesbiana, fueron apropiadas por gran parte de la comunidad homosexual, apartándolas del significado peyorativo que históricamente habían tenido. Lo mismo sucedió con símbolos como el triángulo rosa invertido, con el que los nazis marcaban a los presos homosexuales en los campos de concentración, el cual pasó a convertirse en uno de los emblemas del Orgullo Gay. En México pasó algo parecido con el número 41 y la historia de la gran redada de 1901. Esta apropiación tuvo que ver en gran medida con que el acontecimiento histórico referido era una redada policiaca, un acto de abuso de poder del que los homosexuales fueron víctimas continuas durante todo el siglo XX y se agudizó en las décadas de 1970 y 1980, razón por lo que una de las principales exigencias en las primeras marchas del Orgullo homosexual en la ciudad de México fue ponerle fin a dichos actos.

El cambio de sentido del número 41 se vio, por ejemplo, en la aparición de discotecas gays que hacían referencia a la redada de 1901, como "Disco Club 41" y "El famoso 42". Pero, sobre todo, con la publicación de la revista 41, Soñar fantasmas, cuyo nombre también hace referencia a la primera novela de temática gay en México, 41, o el muchacho que soñaba fantasmas de Paolo Po, y cuyo lo-

4 "El término queer operó como una práctica lingüística cuyo propósito fue avergonzar al sujeto que nombra o, antes bien, producir un sujeto a través de esa interpelación humillante. La palabra queer adquiere su fuerza precisamente de la invocación repetida que terminó vinculándola con la acusación, la patologización y el insulto. Ésta es una invocación mediante la cual se forma, a través del tiempo, un vínculo social entre las comunidades homofóbicas. La interpelación repite, como en un eco, interpelaciones pasadas y vincula a quienes la pronuncian, como si éstos hablaran al unísono a lo largo del tiempo. En este sentido, siempre es un coro imaginario que insulta iqueer! (Butler, p. 318). gotipo también contiene el triángulo rosa invertido (Hernández, 2001).

$\mathrm{Al}$ inicio del siglo XXI, justo en el centenario de la gran redada de los 41 , se develó el primer monumento público sobre la cuestión homosexual en México en la explanada del Centro Cultural José Martí en la ciudad de México. Se trata de una placa que consta de dos piezas, a la izquierda un relieve en bronce del escultor Reynaldo Velázquez y a la derecha un breve texto del Carlos Monsiváis, el cual contiene las siguientes líneas: "A cien años; en desagravio de las 41 víctimas de la primera redada homófoba del siglo XX en México. Por el pleno respeto a los derechos humanos y civiles de gays y lesbianas". El relieve de Velázquez representa un número 41, formado por dos figuras de hombres desnudos. En la primera, al hombre se le ve de frente haciendo "un cuatro", como el que se les pide hacer a las personas ebrias como prueba de sobriedad cuando son detenidas por la policía. En la segunda de las figuras, el hombre también está haciendo "un cuatro", pero como se le ve de perfil forma el número uno (García, 2001).

\section{Años recientes}

Tras los logros legales del movimiento LGBTIQ no solo en la ciudad de México sino a nivel nacional, con el reconocimiento del matrimonio igualitario por parte de la Suprema Corte de Justicia de la Nación, se han seguido realizando representaciones artísticas relacionadas con los 41 maricones. Una de ellas fue el monólogo El Ninfo del actor y dramaturgo sonorense Marcos Maytorena, presentado a inicios del 2016 en el Colegio de Sonora como introducción a la presentación del libro Chulos y coquetones del periodista Antonio Bertrán. Éste último tomó ese

\footnotetext{
${ }^{5}$ Véase: "Relieve en bronce" de Reynaldo Velázquez. Fuente: http://www.jornada.unam. mx/2001/11/17/02an1cul.html
} 


\section{(Arte)}

título de los versos de uno de los folletos protagonizados por las ilustraciones de Posada, el cual dice: “Aquí están los maricones, muy chulos y coquetones". Bertrán le pone ese título y coloca en la portada caricaturas coloridas de sus entrevistados -artistas y activistas del mundo gay- como un acto más de reivindicación y apropiación de aquello que antes tenía un connato peyorativo, convirtiéndolo en motivo de orgullo.

Al inicio de la presentación Maytorena entró en escena vestido con un atuendo

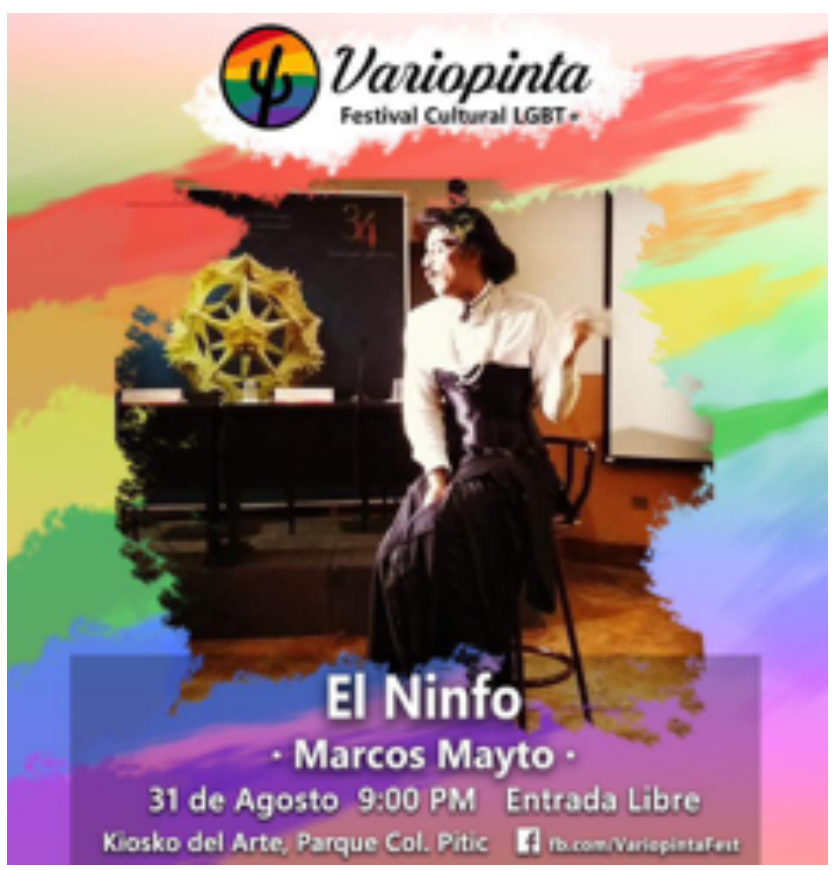

inspirado en las caricaturas de Posada: falda larga, camisa blanca envuelta por un corsé, collares de perlas, maquillaje cargado y un pañuelo en su mano, sin olvidar su distintivo bigote. El personaje, que pertenecía al grupo de los 41 fue llamado "El Ninfo" por Maytorena probablemente haciendo referencia a la novela Historia de Chucho el Ninfo, de José Tomás de Cuéllar, único antecedente literario que retrata a un aparente homosexual mexicano de finales del siglo XIX. El ninfo cuenta lo que aconteció esa noche de noviembre de 1901, entre su tartamudeo y nerviosismo, desde su estancia en Nueva York, a donde fue enviado por su familia tratando de ocultar su vergüenza en un lugar lejano. Maytorena logra transmitir la angustia de un personaje condenado a vivir bajo la sombra de la injuria, convirtiendo a este monólogo en un ejercicio de memoria histórica que constata en el espectador que la identidad gay mexicana

Promocional en facebook de " $E l$ Ninfo” en Variopinta Fest 2016. Fuente: https://www.facebook.com/ VariopintaFest/photo

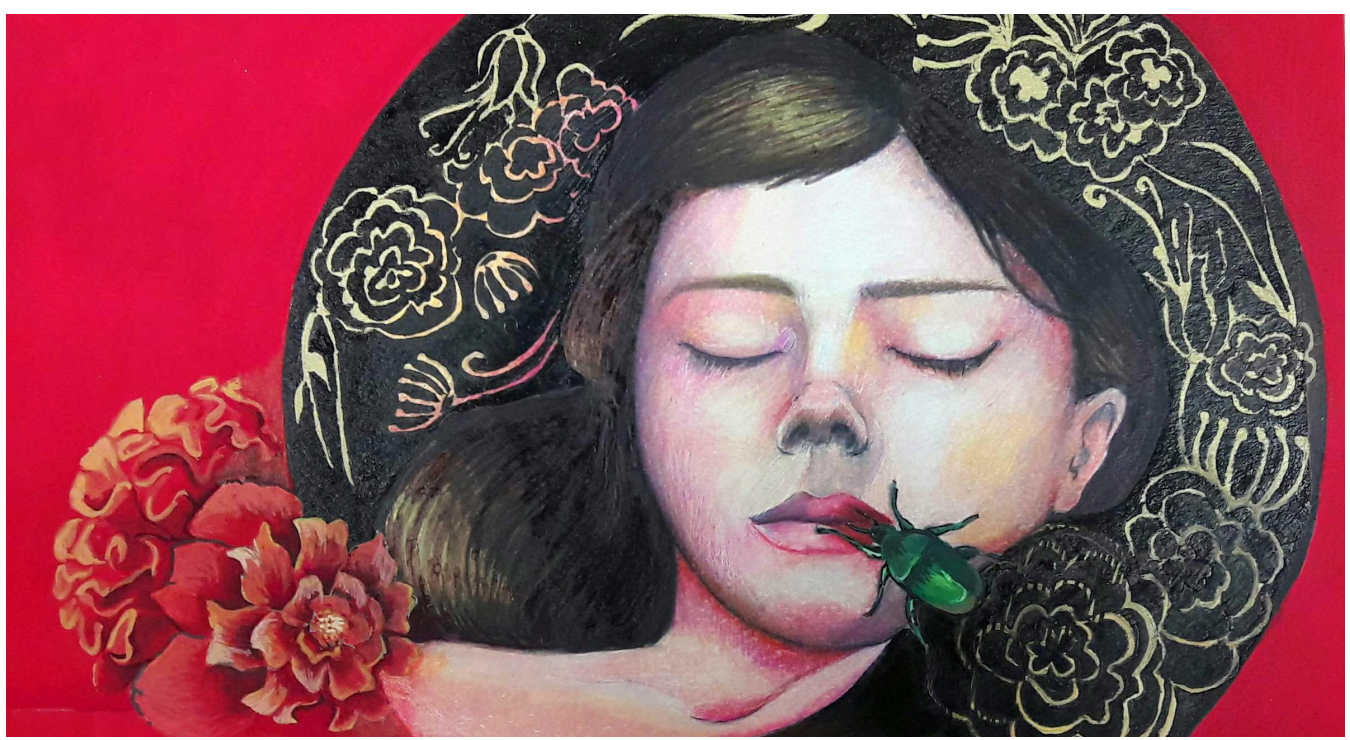


tiene su origen en la injuria y el abuso de poder del que fueron víctimas aquellos 41 chulos y coquetones.

Meses después, en septiembre de 2016, Maytorena volvió a presentar El Ninfo en el marco del Variopinta Fest (1), un festival de artes escénicas de temática LGBTIQ, que organizó la Red Ciudadana Hermosillo Incluyente con el objetivo de contrarrestar el discurso de odio que comenzó a difundir el Frente Nacional por la Familia, organización conservadora que rechazó la iniciativa presidencial sobre el matrimonio igualitario, la adopción en parejas del mismo sexo y la ley de cambio de identidad de género. Este grupo de poder convocó a una marcha donde sobresalió el hecho de que las representaciones estereotipadas de la homosexualidad masculina y femenina, como seres inmorales, nefandos y decadentes, siguen existiendo a pesar de los avances que en las últimas décadas ha logrado el discurso del respeto a la diversidad amorosa y sexual. En medio de esta lucha de representaciones, los conservadores y sus ideas retrógradas sobre la familia y la sexualidad lograron su objetivo y la iniciativa presidencial no fue aprobada en el Congreso, sin embargo, la Suprema Corte de Justicia de la Nación avaló la llamada "adopción gay" declarando que la orientación sexual y el tipo de familia son irrelevantes para adoptar". Es claro que esta lucha de representaciones no va terminar aún, pero aquellos que pretenden continuar con el legado de la representación injuriosa seguirán enfrentándose a los mecanismos de los grupos progresistas que defienden los derechos humanos de las minorías sexuales, quienes llevan tiempo creando sus propias representaciones y que han sabido apropiarse y resignificar aquello que antes era injuria convirtiéndolo en motivo de orgullo, como es el caso la gran redada del baile de los 41 maricones.

\section{Bibliografía}

Butler, J. (2010). Cuerpos que importan. Sobre los límites materiales y discursivos del "sexo". Buenos Aires: Paidós.

Castrejón, Eduardo. (2013). Los cuarenta y uno: novela crítico-social. México, D.F.: UNAM.

Eribon, D. (2001). Reflexiones sobre la cuestión gay. Barcelona: Anagrama.

García, A. (2001). A un siglo de la redada de los 41. En: http://www.jornada.unam. mx/2001/11/17/02an1cul.html

Harris, Juan. (2016). Conferencia: “Los 41, ¿último capítulo?”. En: https://radioteca. net/audio/hilacha-los-41-ultimo-capitulo-juan-carlos-harris/

Hernández, Miguel. (2001). Los cuarenta y uno, cien años después. En: http://www. jornada.unam.mx/2001/12/09/sem-hernandez.html

Marquet, A. (2009). El arte homosexual en México (a vuelo de pájaro). En: http://ciudadaniasx.org/el-arte-homosexual-en-mexico-a-vuelo-de-pajaro/

McKee, R. (2013). Los cuarenta y uno: La novela perdida de Eduardo Castrejón. En Eduardo A. Castrejón, Los cuarenta y uno: novela crítico-social (pp. 7-34). México, D.F.: UNAM.

Monsiváis, C. (2010). Que se abra esa puerta. México, D.F.: Paidós.

Monsiváis, C. (2013). Los 41 y la gran redada. En Eduardo A. Castrejón, Los cuarenta y uno: novela crítico-social (pp. 35-62). México, D.F.: UNAM. 